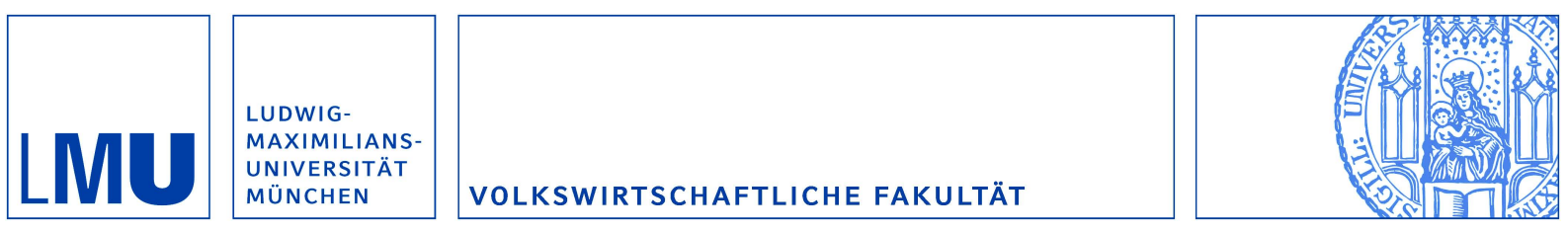

Siemens, Ferdinand von:

Bargaining under Incomplete Information, Fairness, and the Hold-Up Problem

Munich Discussion Paper No. 2005-2

Department of Economics

University of Munich

Volkswirtschaftliche Fakultät

Ludwig-Maximilians-Universität München

Online at https://doi.org/10.5282/ubm/epub.518 


\title{
Bargaining under Incomplete Information, Fairness, and the Hold-Up Problem *
}

\author{
Ferdinand von Siemens \\ University of Munich ${ }^{\dagger}$
}

This Version: February 2005

\begin{abstract}
In the hold-up problem incomplete contracts cause the proceeds of relation-specific investments to be allocated by ex-post bargaining. The present paper investigates the efficiency of incomplete contracts if individuals have heterogeneous preferences implying heterogeneous bargaining behavior and - equally important - preferences are private information. As the sunk investment costs can thus potentially signal preferences, they can influence beliefs and consequently bargaining outcomes. The necessities of signalling are shown to generate very strong investment incentives. These incentives are based on the desire not to reveal information that is unfavorable in the ensuing bargaining. After finding all perfect Bayesian equilibria in pure strategies, the paper derives the necessary and sufficient conditions under which it is optimal to invest and trade efficiently.
\end{abstract}

JEL Classification: Cr0, D23, D63, D82, J33, K12, L22

Keywords: Incomplete Contracts, Hold-Up, Fairness, Bargaining under Incomplete Information, Signalling.

${ }^{*}$ The paper is based on Chapter 1 of my Ph.D. thesis. I would like to thank Björn Bartling, Sven Rady, Ray Rees, Markus Reisinger, Klaus Schmidt, and seminar participants at the ESEM 2003, the WZB, and the University of Innsbruck for helpful comments. Financial support from the German Science Foundation (DFG) through the SFB/TR 15 is gratefully acknowledged.

${ }^{\dagger}$ E-mail: ferdinand.vonsiemens@lrz.uni-muenchen.de 


\section{Introduction}

\section{Motivation}

The theory of incentives recommends that contracts should be 'complete' in the sense of using all relevant and contractable information in order to minimize efficiency losses due to asymmetric information. ${ }^{1}$ In this sense numerous - perhaps even most - contracts observed in the real world are highly incomplete. For example, a professor's salary rarely conditions directly on his publication record, workers often do not receive performance pay, and many trade contracts are silent on a number of important details. Surprisingly, these incomplete contracts often seem to work reasonably well.

This paper proposes an explanation for this observation based on the hold-up problem pioneered by Grout (1982), Grossman and Hart (1986), and Hart and Moore (1990). In these models the proceeds of previously sunk, relationship-specific investments are allocated by bargaining. As no complete contract protects the investors from ex-post exploitation during this bargaining, ex-ante investment incentives are inefficiently low. However, these results very much depend on the assumption that the bargaining outcome is independent of the sunk investment costs.

The model steps in at this point by augmenting an otherwise standard hold-up model with the following two assumptions, both of which are based on an overwhelming experimental evidence on simple bargaining games. ${ }^{2}$ First, individuals have heterogeneous preferences generating heterogeneous bargaining behavior. Second, preferences are private information such that the bargaining situations emerging from contractual incompleteness are characterized by incomplete information. Given these assumptions, beliefs about the other individual's preferences influence strategic behavior. If preferences are private information, it can thus be optimal to choose certain actions prior to the bargaining in order not to reveal unfavorable information. Indeed, the model shows that the necessities of signalling can generate investment incentives sufficiently strong as to prompt efficient outcomes even in the presence of a hold-up situation.

\footnotetext{
${ }^{1}$ See, for example, Holmström (1982) or Laffont and Tirole (1993).

${ }^{2}$ For a summary see, for example, Güth, Schmittberger, and Tietz (1990) or Camerer and Thaler (1997).
} 


\section{Summary of the Model}

Specifically, consider a buyer and a seller who bargain over the division of some trade surplus created by a sunk, relationship-specific investment of the seller. The bargaining is modelled as an ultimatum game with the buyer making a take-it-or-leave-it offer to the seller. There are two types of sellers differing with respect to their preferences and thus their bargaining behavior. Whereas a selfish seller accepts all offers giving him a weakly positive share of the trade surplus, a fair-minded seller rejects even strictly positive offers if he perceives them as "unfair" in the sense of giving him less than a certain, strictly positive share of the trade surplus. Although based on the notion of fairness, the present paper does not concentrate on some particular interpretation of preferences like reciprocity or inequity aversion. The only important assumption is that individuals differ with respect to their bargaining behavior, and that the underlying preferences are unobservable.

There are the following results. If the seller's type is observable, the buyer incorporates this information in his bargaining strategy. In equilibrium the selfish seller then receives a smaller share of the trade surplus than the fair-minded seller, whose investment incentives are thus improved. But as not even a fair-minded seller gets the entire trade surplus, both types of sellers still under-invest, and full efficiency cannot be reached.

However, if the seller's preferences are unobservable, the seller's investment might signal his preferences. As it is now enough to appear fair-minded in order to induce the buyer to behave as if one were fair-minded, incomplete information can generate very strong investment incentives for both types. The present paper first characterizes all perfect Bayesian equilibria in pure strategies. It then derives the conditions under which there exists an equilibrium where both types of sellers invest efficiently and the good is always traded. As with most signalling games there exists a multiplicity of equilibria that differ widely with respect to their efficiency. Unfortunately, standard refinements are shown to have no bite. However, if unexpectedly high investments are interpreted as stemming from a fair-minded seller whereas unexpectedly low investments make the buyer believe the seller to be selfish, only pooling equilibria with relatively high investments survive. The analysis thus offers an argument why incomplete contracts need not be as inefficient as predicted by contract theory. 


\section{Related Literature}

The above results essentially stem from the link between sunk investment costs and bargaining outcomes. In the present model this link arises from the investor's desire or need to signal information on his preferences that is important in the ensuing bargaining. Although none of the following articles captures this idea, the following two strands of research are most closely related amongst the seemingly unbounded literature on incomplete contracts. ${ }^{3}$

The first group of papers emphasizes the impact of social preferences on efficiency while assigning no major role to incomplete information. The first two papers focus on the role of communication prior to the bargaining. Ellingsen and Johannesson (2002a) argue that social preferences and communication can provide a focal point in bargaining games with multiple equilibria. If individuals then coordinate on an equilibrium with efficient investment incentives, the hold-up problem disappears. In Ellingsen and Johannesson (2004) individuals care for both fairness and consistency. They therefore stick to their announced bargaining behavior such that communication is no longer cheap talk. Both papers provide experimental evidence which - especially in Ellingsen and Johannesson (2004) - can also be interpreted in accordance with the present paper. First, the importance of communication as a signalling device might hint at the relevance of incomplete information on the investor's preferences. Second, even without communication there is more investment than is to be expected with standard, selfish preferences. However, in both the above articles the argument hinges on the restriction to a binary investment choice. It is not clear whether the results carry over to a continuum of investment levels.

Just as the present model, Ewerhart (2004) allows for a continuum of investment levels. He analyzes the impact of inequity aversion in alternating-offer bargaining. He essentially assumes that individuals care for an equal division of payoffs net of investment costs. In equilibrium an individual's share of the trade surplus thus increases in his investment. This improves incentives. However, in the above three articles the investment costs enter directly in the utility functions evaluating the bargaining outcomes. In contrast to this, the present

\footnotetext{
${ }^{3}$ There exists another group of papers based on evolutionary game theory. See Ellingsen and Robles (2002), Tröger (2002), and Carmichael and MacLeod (2003).
} 
paper creates a more indirect link between investments and bargaining outcomes arising from incomplete information.

The second group of articles explicitly analyzes the role of incomplete information. As in the above articles, Ellingsen and Johannesson (2002b) assume that individuals care for an even distribution of monetary payoffs net of investment costs. They emphasize that incomplete information on the investor's investment costs can create uncertainty about the fairness of a bargaining proposal. Incomplete information thus opens the doors for inefficient bargaining breakdowns. In contrast to Ellingsen and Johannesson (2002b) incomplete information has a positive impact on efficiency in Gul (2001). In his model the investment is unobservable such that mixed strategies cause strategic uncertainty with respect to the investor's valuation. Due to an argument similar to the Coase conjecture, the hold-up problem disappears in the limit if there are repeated offers and individuals become very patient. Apart from the different mechanics at work - investments clearly cannot signal anything if they are unobservable results differ. Unlike in the present model the hold-up problem persists if the investment is followed by a single take-it-or-leave-it offer in Gul (2001).

\section{Structure of the Paper}

The paper is organized as follows. Section 2 introduces the basic setting, defines the seller's preferences and the informational structure, and introduces perfect Bayesian equilibrium as the relevant equilibrium concept. Section 3 derives the equilibrium payoffs in the bargaining game characterized by a certain investment and corresponding belief of the buyer. Depending on how the buyer forms his beliefs, this yields the seller's payoff conditional on his investment. The set of all pooling and separating equilibria can then be described easily. Section 4 investigates the implications for the efficiency of incomplete contracts. With the help of equilibrium refinements it discusses whether all existing equilibria are equally plausible. Section 5 provides some anecdotal evidence and concludes. All formal proofs are to be found in the appendix. 


\section{The Model}

\section{Investment, Bargaining, and Sequence of Actions}

Consider a buyer and a seller who can trade one unit of a good. The good's quality $i \in \mathbb{R}^{+}$is determined by an investment of the seller, causing him costs $i$. Once these costs are sunk, the absence of a complete trade contract causes terms of trade to be determined by bargaining. The bargaining process is modelled as an ultimatum game with the buyer as proposer and the seller as responder. First, the buyer proposes a share $p \in \mathbb{R}$ of the trade surplus to be given to the seller. Second, the seller can accept or reject the buyer's offer. Let $a \in\{0,1\}$ describe the seller's acceptance decision, where $a$ is unity if he accepts. If the seller accepts the buyer's proposal $p$, then the good is traded, the seller receives share $p$ of the trade surplus, and the buyer consumes the good. If the buyer rejects $p$, then the good is not traded, and the seller consumes the good himself.

\section{Preferences, Types, and Information}

Experimental investigations of the ultimatum game exhibit the following behavioral patterns. First, some responders reject strictly positive proposals. Second, responders are heterogeneous, some reject proposals accepted by others. Finally, bargaining breakdowns occur, which suggests that the minimum proposal a particular responder just accepts seems to be unobservable to the proposer. The following preferences generate exactly such bargaining behavior, where the internal motivations captured in the preferences will be discussed once the implied bargaining behavior has been characterized.

Let $\phi: \mathbb{R}^{+} \rightarrow \mathbb{R}^{+}$denote the buyer's value from consuming a good of quality $i$, and $\psi: \mathbb{R}^{+} \rightarrow \mathbb{R}^{+}$the seller's value from consuming the good himself. Depending on the good's quality $i$, the buyer's proposal $p$, and the seller's acceptance decision $a$, the buyer's payoff is defined as

$$
u_{b}(i, p, a)=a(1-p)[\phi(i)-\psi(i)]
$$

In case of trade the buyer is exclusively interested in his share of the trade surplus. If the good is not traded, he receives a payoff normalized at zero. 
In order to capture the heterogeneity of responder behavior, the seller can be either selfish or fair-minded. Let $\theta \in\{s, f\}$ denote the seller's type, where $\theta=s$ indicates that the seller is selfish and $\theta=f$ indicates that he is fair-minded. The seller's type is taken to be private information and thus unobservable to the buyer. However, it is common knowledge that the ex-ante probability for the seller to be fair-minded is $\pi \in[0,1]$.

Depending on the good's quality $i$, the proposal $p$, and the acceptance decision $a$, let

$$
u_{s}(i, p, a)=a p[\phi(i)-\psi(i)]+\psi(i)-i
$$

denote a selfish seller's payoff. Equally, let

$$
u_{f}(i, p, a)= \begin{cases}u_{s}(i, p, a) & \text { if } p \geq \gamma \\ (1-a) \psi(i)-i & \text { if } p<\gamma\end{cases}
$$

denote a fair-minded seller's payoff for some parameter $\gamma \in] 0,1[$. Thus, a fair-minded seller has the same preferences as a selfish seller whenever $p$ is weakly larger than $\gamma$. However, if $p$ is strictly smaller than $\gamma$, the fair-minded seller receives a much lower payoff than the selfish seller in case of acceptance. Note that the fair-minded seller's preferences have a discontinuity at $p=\gamma$ the implications of which are discussed in Section 3. There are the following simplifying assumptions with respect to $\phi$ and $\psi$.

Assumption $1 \phi(0)>\psi(0)=0$.

Assumption $2 \phi$ is strictly, $\psi$ is weakly increasing.

Assumption $3 \phi$ and $\psi$ are strictly concave.

Assumption $4 \phi$ and $\psi$ are twice differentiable.

Assumption $5 \phi^{\prime}(i)>\psi^{\prime}(i)$ and for all $i$.

Assumption $6 \lim _{i \rightarrow 0} \psi^{\prime}(i)>+\infty$ and $\lim _{i \rightarrow \infty} \phi^{\prime}(i)=0$.

These assumptions imply

Lemma 1 For all $k \in[0,1]$, the function $k[\phi(i)-\psi(i)]+\psi(i)-i$ has a unique, positive, and finite maximizer. The corresponding maximum is positive. Both maximizer and maximum are strictly increasing in $k$.

Essentially, the above assumptions render all the seller's maximization problems in the ensuing analysis well behaved. 


\section{Bargaining Behavior and Interpretation of Preferences}

The seller's preferences have the following implications for his bargaining behavior. For given investment $i$, it is optimal for a seller of type $\theta$ to accept proposal $p$ only if $u_{\theta}(i, p, a) \geq \psi(i)-i$. Since Assumption 1 and 5 imply $\phi(i)-\psi(i)>0$,

\section{Lemma 2 (Seller's Bargaining Behavior) For all investments $i$,}

1. only if $p \geq 0$, it is optimal for the selfish seller to accept, and

2. if and only if $p \geq \gamma$, it is optimal for the fair-minded seller to accept.

Note that both types of sellers strictly prefer to accept a proposal $p=\gamma$, but that the selfish seller is indifferent between accepting and rejecting $p=0$. Thus, $p \geq 0$ is necessary but not sufficient to make the selfish seller always accept. Note that even a fair-minded seller's acceptance decision is independent of the investment. Contrary to the literature cited in the introduction, sunk costs are thus sunk when looking at the seller's preferences. In fact, in the present model sunk costs do not impact on the bargaining outcome in any way other than by influencing the buyer's belief.

The above preferences generate the behavior observed in the ultimatum game. The present paper does not focus on a particular motivation for this behavior. Instead, qualitatively the same results could be obtained with the following modelling alternatives. First, some but not all sellers are driven by intention based reciprocity à la Rabin (1993). Reciprocal individuals consider offers $p$ marginally less than $\gamma$ an unfriendly act and thus reject. It is unobservable whether an individual is reciprocal or not. Second, the bargaining in modelled as in Crawford (1982), where sellers could try to strengthen their bargaining power by announcing to reject all proposals below some threshold $\gamma$ ex-ante. Sellers differ with respect to the back-down costs they incur if they nevertheless accept a proposal $p<\gamma$, and there is incomplete information on the seller's back-down costs. Finally, a fair-minded seller can be viewed as inequity averse in the spirit Fehr and Schmidt (1999) or Bolton and Ockenfels (2000) if the suffering is taken to be infinitely strong whenever his share of the trade surplus is less than the reference share $\gamma$. Moreover, von Siemens (2004) derives the same results n a model with finite inequity aversion if the bargaining game is suitably adapted. More on this at the end of Section 3. 


\section{Efficiency}

After defining payoffs it is now possible to characterize the efficient investment. For all strictly positive investments $i$ a strictly positive trade surplus $\phi(i)-\psi(i)$ is lost in case of a bargaining breakdown. Thus, the good should always be traded. The efficient investment $i_{e}$ defined as

$$
i_{e}=\arg \max \{\phi(i)-i\}
$$

thus maximizes the pie $\phi(i)-i$ to be distributed between buyer and seller.

\section{Strategies and Perfect Bayesian Equilibria}

As the bargaining behavior of a selfish and a fair-minded seller differ for $p<\gamma$, the buyer might like to condition his proposal on the seller's type. As the seller's type is unobservable, the ultimatum game starting after the seller's investment is a bargaining game under incomplete information. Since the seller's investment is a potential signal for his type, let $\mu: \mathbb{R}^{+} \rightarrow[0,1]$ denote the probability with which the buyer believes the seller to be fair-minded after observing investment $i$.

The present paper restricts attention to perfect Bayesian equilibria (PBE) in pure strategies. A pure strategy for the seller determines for each type $\theta \in\{f, s\}$ an investment $i_{\theta}$ and acceptance rule $a_{\theta}: \mathbb{R} \rightarrow\{0,1\}$ describing the acceptance decision conditional on the buyer's proposal $p$. Subscript $\theta$ serves a double role: it indicates the seller's type and that $a_{\theta}$ is a function and not a single acceptance decision $a$. Note that by Lemma 2 even a fair-minded seller's acceptance decision is independent of the investment. Thus, $a_{\theta}$ need not condition on the investment. A pure strategy for the buyer determines a proposal $p_{b}: \mathbb{R}^{+} \rightarrow \mathbb{R}$ conditional on the observed investment $i$. Subscript $b$ indicates that $p_{b}$ is a function and not a single proposal $p$.

Let $\mathcal{C}(i, \mu)$ denote the ultimatum game starting after the seller's investment $i$. A PBE then has the following properties. First, in every ultimatum game $\mathcal{C}\left(i, \mu^{*}(i)\right)$, the buyer's equilibrium strategy $p_{b}^{*}$ and the seller's equilibrium acceptance rule $a_{\theta}^{*}$ are mutually optimal given the equilibrium belief $\mu^{*}(i)$. In addition, the seller's acceptance rule is to comply with the spirit of subgame-perfection. Second, the buyer's belief $\mu^{*}(i)$ is formed according to Bayes' rule whenever possible. If investment $i$ is never chosen in equilibrium, Bayes' 
rule is not applicable. In this case the equilibrium belief $\mu^{*}(i)$ may be set freely. Finally, the seller's equilibrium investment $i_{\theta}^{*}$ for both $\theta \in\{f, s\}$ is optimal conditional on the anticipated equilibrium play in the ultimatum games $\mathcal{C}\left(i, \mu^{*}(i)\right)$. Let $U_{s}^{*}, U_{f}^{*}$, and $U_{b}^{*}$ denote the equilibrium payoff of the selfish seller, the fair-minded seller, and the buyer, respectively.

Since only pure strategies are considered, there are only two classes of equilibria, pooling and separating equilibria. In a pooling equilibrium both types of sellers choose the same equilibrium investment, $i_{s}^{*}=i_{f}^{*}=i^{*}$. Since thus $\mu^{*}\left(i^{*}\right)=\pi$, there is no updating of beliefs on the equilibrium path. In a separating equilibrium both types of sellers choose different equilibrium investments, $i_{s}^{*} \neq i_{f}^{*}$. They thus reveal their type, $\mu^{*}\left(i_{s}^{*}\right)=0$ and $\mu^{*}\left(i_{f}^{*}\right)=1$.

\section{$3 \quad$ Perfect Bayesian Equilibria}

\section{Equilibrium Play in the Ultimatum Game}

Building on Lemma 2 the equilibrium behavior in any ultimatum game $\mathcal{C}(i, \mu)$ can be characterized as follows.

Lemma 3 (Equilibrium Bargaining Behavior) In any pure strategy perfect Bayesian equilibrium the equilibrium behavior in any ultimatum game $\mathcal{C}(i, \mu)$ is characterized as follows.

1. If $\mu>\gamma$, the buyers proposes $p=\gamma$. Both types of sellers accept and receive equilibrium payoff $\gamma[\phi(i)-\psi(i)]+\psi(i)-i$.

2. If $\mu<\gamma$, the buyers proposes $p=0$. The selfish seller accepts, the fair-minded seller rejects, and both types of sellers receive equilibrium payoff $\psi(i)-i$.

3. If $\mu=\gamma$, equilibrium play can resemble both of the above characterizations generating identical equilibrium payoffs.

Two alternatives are potentially optimal for the buyer. Either he claims a relatively small share of the trade surplus, $p=\gamma$, and trades with certainty. Or he claims the entire trade surplus, $p=0$, but trades only if the seller is selfish. As the probability of trade is $\mu$ in the latter case, this belief determines which of the above alternatives is optimal. Essentially, the buyer bargains aggressively if and only if he is sufficiently convinced that the seller is selfish. 
The maximum payoff the seller can get if the buyer believes him to be selfish with certainty will play a special role in the ensuing analysis. Define this payoff as

$$
U_{0}=\max _{i}\{\psi(i)-i\}
$$

with corresponding maximizer $i_{0}$.

\section{Complete Information Benchmark}

To disentangle the impact of fairness and incomplete information this section analyzes the efficiency of incomplete contracts if the seller can be fair-minded or selfish and his preferences are observable. As the buyer then knows the seller's type, his bargaining behavior is independent of the seller's investment. After investing $i$ the selfish seller always receives a payoff of $\psi(i)-i$, whereas the fair-minded seller always receives a payoff of $\gamma[\phi(i)-\psi(i)]+\psi(i)-i$. The equilibrium investments maximize these payoffs, therefore

Proposition 1 (Complete Information Equilibrium) Suppose the seller's type is observable. Then there exists a unique subgame-perfect Nash equilibrium in which the good is always traded and

$$
i_{s}=\arg \max _{i}\{\psi(i)-i\} \quad \text { and } \quad i_{f}=\arg \max _{i}\{\gamma[\phi(i)-\psi(i)]+\psi(i)-i\}
$$

characterize the unique equilibrium investments. As $i_{s}<i_{f}<i_{e}$ both types of sellers under-invest.

As he receives a larger share of the trade surplus, a fair-minded seller invests more than a selfish seller. But since not even the fair-minded seller receives all the trade surplus, both types still invest less than the efficient investment. Fairness thus mitigates, but does not solve the hold-up problem.

\section{Pooling Equilibria}

Investment incentives change radically if preferences are unobservable. If the seller's type is private information, the buyer's belief depends on the seller's investment. In a pooling equilibrium both types of sellers choose the same equilibrium investment $i^{*}$. On the equilibrium path the buyer thus learns nothing about the seller's type and keeps his 
prior belief $\pi$. The equilibrium payoff of both types of sellers is then determined by Lemma 3 .

Investment $i^{*}$ can be supported as equilibrium investment in a pooling equilibrium if and only if there are no profitable deviations. As in a pooling equilibrium both types of sellers always choose the same investment $i^{*}$, deviating and choosing any other investment $i$ is out-of-equilibrium. Since then Bayes' rule cannot be applied, the buyer's out-of-equilibrium belief $\mu^{*}(i)$ can be chosen freely. By Lemma 3 it is most disadvantageous for both types of sellers if the buyer believes him to be selfish with certainty. Both types of sellers then get a deviation payoff of $\psi(i)-i$. Choosing this most unfavorable belief for all out-ofequilibrium investments, the seller can thus get a deviation payoff up to $U_{0}$ by maximizing over his deviation investment. Consequently, an investment $i^{*}$ can be supported in a pooling equilibrium if and only if both types get an equilibrium payoff $U_{\theta}^{*}$ weakly larger than $U_{0}$. Building on

Lemma 4 For all $\gamma \in] 0,1[$, the set

$$
I=\left\{i \in \mathbb{R}^{+}: \gamma[\phi(i)-\psi(i)]+\psi(i)-i \geq U_{0}\right\}
$$

forms a non-empty, bounded, and closed interval $[\underline{i}, \bar{i}] \in \mathbb{R}^{+}$.

the set of pooling equilibria can be characterized as follows.

\section{Proposition 2 (Pooling Equilibria)}

1. If $\pi \geq \gamma$, there exists a continuum of pooling equilibria in which both types of sellers invest $i^{*} \in I$ and the good is always traded.

2. If $\pi<\gamma$, there exists a unique pooling equilibrium in which both types of sellers invest $i_{0}$ and the good is traded if and only if the seller is selfish.

The above proposition is based on the following intuition. Although the investment choice is continuous, the buyer's equilibrium beliefs create a discontinuity in the seller's objective function. If the seller chooses an investment just marginally lower than the equilibrium investment, the buyer's belief changes. This affects his proposal and thus causes a payoff jump for the seller. Given the buyer rather believes the seller to be selfish when observing an out-of-equilibrium investment, $\mu^{*}(i)<\gamma$, he then bargains aggressively and claims the entire 
trade surplus. In equilibrium, a seller can thus get the large share $\gamma$ of the trade surplus if and only if he chooses the equilibrium investment $i^{*}$. This can generate very strong investment incentives.

\section{Separating Equilibria}

Although the preferences of the selfish and the fair-minded seller are very similar, they are not identical whenever the buyer proposes $p$ smaller than $\gamma$ and the seller accepts. Indeed, there exist separating equilibria. However, due to the following lemma the set of separating equilibria is very degenerate. It is included here more for the sake of showing that the signalling is no cheap talk.

Lemma 5 In every PBE, both types of sellers get the same equilibrium payoff, $U_{s}^{*}=U_{f}^{*}$.

Each type of seller can get the other typ's equilibrium payoff by mimicking the investment and then optimizing over the acceptance decision. In a separating equilibria both types of sellers must thus be indifferent between their and the other type's equilibrium investment. As both reveal their type in equilibrium, the buyer proposes $p_{b}^{*}\left(i_{s}^{*}\right)=0$ after observing the selfish seller's equilibrium investment. As the selfish seller can get no worse response when deviating, his equilibrium investment must be $i_{0}$ maximizing $\psi(i)-i$. Lemma 5 then implies

Proposition 3 (Separating Equilibria) There exist two separating equilibria in which the selfish seller invests $i_{s}^{*}=i_{0}$, the fair-minded seller invests $i_{f}^{*} \in\{\underline{i}, \bar{i}\}$ as defined in Lemma 4 , and the good is always traded.

In these equilibria, the buyer believes the seller to be selfish with certainty whenever observing any investment other than the fair-minded seller's equilibrium investment $i_{f}^{*}$. When deviating, the fair-minded seller thus faces the proposal $p_{b}^{*}(i)=0$. He rejects, and consequently gets a deviation payoff of $\psi(i)-i$. Even though he can optimally adjust his deviation investment $i$ to the expected proposal, he can get no more than his equilibrium payoff by construction. If the selfish seller mimics the fair-minded seller's equilibrium investment $i_{f}^{*}$, he can falsely convince the buyer that he is fair-minded. But even though he thereby gets the larger share $\gamma$ of the trade surplus, he has to choose the relatively unprofitable investment $i^{*}$, which is either very low, thus generating a low trade surplus, or very high, thus causing very high investment costs. This prevents deviations by the selfish seller. 


\section{Graphical Illustration}

Figure 1 provides a graphical illustration of the above arguments. If the seller's type is observable, the fair-minded seller gets a payoff of $\gamma[\phi(i)-\psi(i)]+\psi(i)-i$ whereas the selfish seller gets a payoff of $\psi(i)-i$ when investing $i$. By choosing the right investment the fairminded seller can move along the upper, whereas the selfish seller can move along the lower curve in Figure 1. Thus, the unique equilibrium investments are $i_{f}$ for the fair-minded, and $i_{0}$ for the selfish seller.

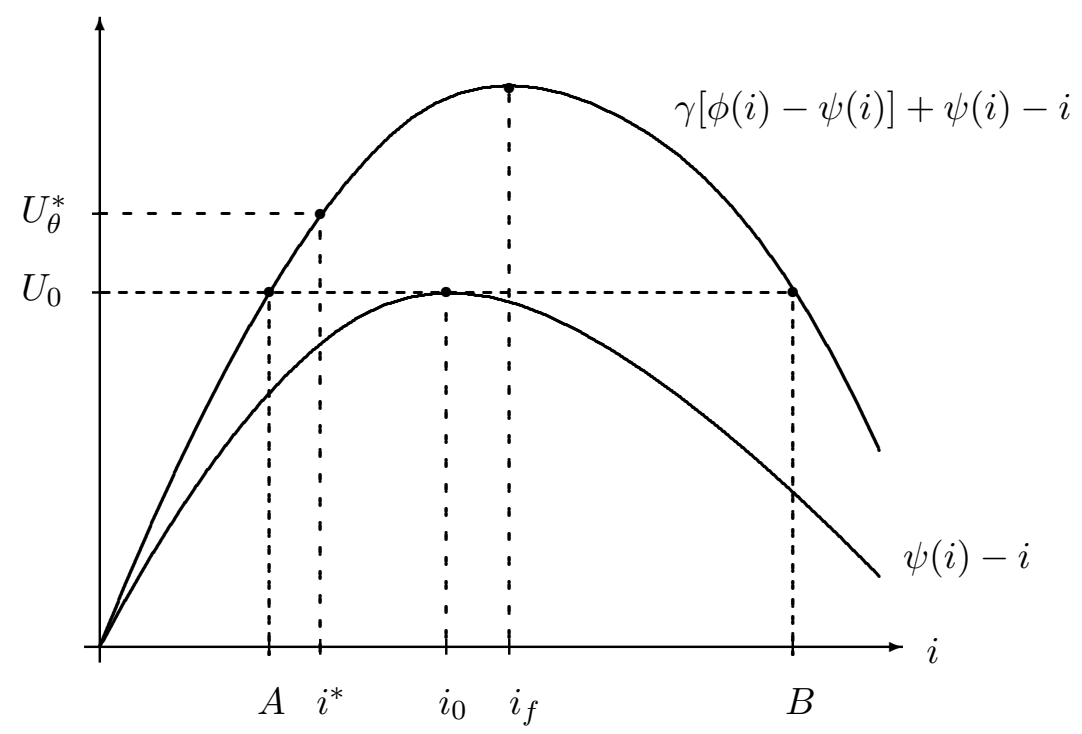

Figure 1: Set of investments supportable as pooling equilibrium for $\pi \geq \gamma$.

If the seller's type is unobservable, his payoff depends on the buyer's belief when investing $i$. In the considered example, the prior belief $\pi$ is sufficiently high as to induce the buyer to make the generous proposal $\gamma$ whenever he does not learn anything about the seller's type. In a pooling equilibrium both types of sellers thus get an equilibrium payoff lying on the upper curve. As this equilibrium payoff must exceed the maximum deviation payoff $U_{0}$, all the investments lying in the interval $[A, B]$ can be supported in a pooling equilibrium. Investment $i^{*}$ provides a - particularly inefficient - example. Moreover, Figure 1 shows that there also exist two separating equilibria in which the selfish seller always invests $i_{0}$ and the fair-minded seller invests either $A$ or $B$. 


\section{The Discontinuity in the Fair-Minded Seller's Preferences}

The discontinuity of the fair-minded seller's preferences at $p=\gamma$ is crucial for the existence of the above PBE. Suppose the seller's preferences are continuous, but that he still receives a payoff of $u_{f}(i, \cdot, 0)=\psi(i)-i$ if the good is not traded. Let $\gamma>0$ denote the cutoff proposal at which such a fair-minded seller is just indifferent between accepting and rejecting. By the very definition of $\gamma$ this implies $u_{f}(i, \gamma, 1)=u_{f}(i, \gamma, 0)=\psi(i)-i$. In any PBE the buyer proposes $p=\gamma$ if he believes the seller to be fair-minded with certainty. Even in this case the fair-minded seller gets exactly his outside option. If instead the buyer believes him to be selfish, he proposes $p=0$. However, as the fair-minded seller thus always receives his outside option independently of the buyer's belief and the corresponding equilibrium proposal, he chooses $i_{0}=\arg \max _{i}\{\psi(i)-i\}$ in equilibrium.

With continuous preferences, the fair-minded seller essentially no longer benefits from the buyer believing him to be fair-minded. Even though the fair-minded seller then receives a larger share of the trade surplus, this payoff bonus is by definition exactly compensated by some sort of suffering, for example from inequity aversion. However, von Siemens (2004) shows that the general idea of the model can be preserved if the bargaining game is suitably extended: it is only crucial that both types of sellers get a rent in excess of their outside option if the buyer rather believes the seller to be fair-minded. As continuous preferences make the exposition more complicated while leaving the general idea unchanged, the present model restricts attention to the simpler case with discontinuous preferences.

\section{Incomplete Information and Investment Incentives}

\section{Incomplete Information and Efficiency}

Incomplete information thus has the following impact on investment incentives. If preferences are observable, the buyer exploits the hold-up situation less - bargains less aggressively - if and only if the seller is fair-minded. Investment incentives are thus improved for the fairminded seller, but remain unchanged for the selfish seller. However, investment incentives for both types might be affected if information is incomplete. In a pooling equilibrium the buyer's reaction to the equilibrium investment is irrespective of the seller's type. If the prior probability of meeting a fair-minded seller is sufficiently high, $\pi \geq \gamma$, the buyer bargains 
as if the seller was fair-minded and offers the seller the high share $\gamma$ of the trade surplus. This improves investment incentives for both types of sellers. As a direct consequence of Proposition 2, Proposition 4 in fact describes the necessary and sufficient conditions under which an efficient PBE exists.

Proposition 4 (Efficient Equilibrium) If and only if $\pi \geq \gamma$ and $i_{e} \in I$, there exists a PBE in which both types of sellers invest efficiently and the good is always traded.

Investment incentives, however, clearly depend on the considered PBE. As with most signalling games there are multiple equilibria that differ enormously with respect to their efficiency. This can best seen with the help of the example in Figure 1. In this case both types of sellers choose an equilibrium investment $i^{*}$ that is even smaller than the selfish seller's complete information equilibrium investment $i_{0}$, but both get a large share of the small trade surplus. The trade surplus might increase when deviating, but the seller's share of the trade surplus then drops. This makes deviating unprofitable. By the same logic there might also exist pooling equilibria in which both types of sellers overinvest. Note that this can happen even though the seller has no formal bargaining power. Moreover, if the prior probability for the seller is sufficiently small, $\pi<\gamma$, the good is no longer traded in case the seller is fair-minded. Incomplete information can thus add a new source of inefficiency by preventing the ex-post efficient trade of the good.

\section{Standard Equilibrium Refinements}

Unfortunately, standard equilibrium refinements cannot reduce the set of equilibrium investments. Consider the most standard and basic refinement, Equilibrium Dominance. ${ }^{4}$ Say a proposal is an equilibrium response if there exists a belief making this proposal optimal for the buyer. Say an out-of-equilibrium investment is equilibrium dominated for a particular type if even the equilibrium response most favorable for this type generates a deviation payoff strictly smaller than his equilibrium payoff. According to Equilibrium Dominance the buyer's belief should then put no probability mass on a particular type when the observed out-of-equilibrium investment is equilibrium dominated for this, but not for the other type. However, in the present setting the buyer's equilibrium response most favorable for both

\footnotetext{
${ }^{4}$ In a setting with only two types Equilibrium Dominance is equivalent to the Intuitive Criterion by Cho and Kreps (1987). For details see the appendix of Chapter 13 in Mas-Colell, Whinston, and Green (1995).
} 
types is to propose $\gamma$, thereby giving both types the same maximum deviation payoff. As both types get the same equilibrium payoff by Lemma 5 , it can never happen that a deviation is equilibrium dominated for one, but not the other type. Consequently, Equilibrium Dominance does not restrict the set of admissible out-of-equilibrium beliefs.

\section{Plausible Beliefs}

Although not based on any established equilibrium refinement the following restriction of out-of-equilibrium beliefs in pooling equilibria seems very consistent with the underlying story and the common notion of fair-minded and selfish preferences. Suppose the seller has put high attention to details, and has thus produced a good of unexpectedly high quality. In this case it seems plausible to believe that the seller would respond aggressively to any unfair behavior by the buyer. Suppose, however, the seller has worked sloppily, and has thus produced a good of unexpectedly low quality. In that case he arguably appears to only care for his own benefit. Thus, say a pooling equilibrium has plausible beliefs if the buyer believes the seller to be fair-minded if he has invested more, and believes the seller to be selfish if he has invested less than the equilibrium investment. This restriction on out-of-equilibrium beliefs has the following impact on the set of pooling equilibria.

\section{Proposition 5 (Pooling Equilibria with Plausible Beliefs)}

1. If $\pi \geq \gamma$, there exists a continuum of pooling equilibria with plausible beliefs in which both types of sellers invest $i^{*} \in I$ satisfying $i^{*} \geq i_{f}$.

2. If $\pi<\gamma$, there exists no pooling equilibrium with plausible beliefs.

Given the above definition of plausible beliefs the seller appears fair-minded when choosing an unexpectedly high investment. As he then gets the high share $\gamma$ of the trade surplus, such a deviation can potentially be profitable even if the seller already gets share $\gamma$ in equilibrium. Whether a profitable deviation exists depends on the equilibrium investment. If it is relatively small, investing more increases the seller's payoff as it gets him closer to the investment $i_{f}$ optimal if the seller gets share $\gamma$ of the trade surplus. If, however, the equilibrium investment is weakly larger than $i_{f}$, investing more is not profitable as it moves him further away from $i_{f}$. Thus, only investments that are weakly larger than $i_{f}$ can be supported as equilibrium choice in a pooling equilibrium with plausible beliefs. In this case even the least efficient pooling 
equilibrium is more efficient than the situation under complete information. Moreover, as the efficient investment $i_{e}$ exceeds $i_{f}$ by Lemma 1, an existing efficient PBE can always be supported as a pooling equilibrium with plausible beliefs.

\section{$5 \quad$ Anecdotal Evidence and Summary}

The following anecdote from the author's personal experience nicely illustrates the relevance of the above results for typical hold-up situations. A nearby neighbor commissioned a mason to embellish his entrance area. Entrance areas are not transferable, so the mason's investment was clearly very relation-specific. Work was mostly carried out on Sundays, which is illicit in Germany. Thus, there was probably no legally enforceable contract. Once the entrance had been finished one should expect the neighbor to exploit the arising hold-up situation. And indeed, he refused to pay the mason anything at all. The mason's reaction, however, is noteworthy. During one of the following nights he emptied buckets full of concrete on the newly paved doorsteps. This costly act had no impact on the bargaining. Moreover, if the neighbor had anticipated the mason's reaction, he presumably would have paid the agreed price. The story therefore suggests that individual exhibit heterogeneous bargaining behavior, and that this behavior is difficult to predict. Finally, the mason personally bandied his criminal behavior about the neighborhood even though this could have resulted in legal consequences. This was probably done in order to build up some reputation for being a tough guy, thus indicating that individuals are aware of the strategic situation characterized by incomplete information.

The interaction of fairness with incomplete information on an individual's preferences lies at the heart of the present model. If preferences are unobservable, changing the investment might change the buyer's belief about the seller's type, thus the buyer's bargaining behavior, and ultimately the seller's share of the trade surplus. This can generate very strong investment incentives. As in most signalling models, there are multiple equilibria differing with respect to their efficiency. But although standard equilibrium refinements have no bite, restricting out-of-equilibrium beliefs in a way consistent with the underlying story generates at least a tendency towards high equilibrium investments. The model thus offers an explanation for the widespread and seemingly successful use of incomplete contracts. 


\section{Appendix}

\section{Proof of Lemma 1}

By Assumption 3, $k[\phi(i)-\psi(i)]+\psi(i)-i$ is strictly concave. By Assumption 6, it has a unique, positive, and finite maximizer. By Assumption 5 and the implicit function theorem, the maximizer is strictly increasing in $k$. By Assumption 1, the corresponding maximum is positive. As $k^{\prime}>k$ implies $k^{\prime}[\phi(i)-\psi(i)]+\psi(i)-i>k[\phi(i)-\psi(i)]+\psi(i)-i$ for all $i$, it is strictly increasing in $k$.

Q.E.D.

\section{Proof of Lemma 3}

a) Suppose the buyer holds belief $\mu$ after observing investment $i$. By Lemma 2 , setting $p>\gamma$ and $p \in] 0, \gamma[$ cannot be optimal, as decreasing $p$ then increases the buyer's payoff in case of trade while leaving the probability of trade unaffected. Thus, in any pure strategy Bayesian equilibrium the buyer sets $p \in\{0, \gamma\}$.

b) Consider $p=\gamma$. As both types of sellers always accept by Lemma 2, this generates equilibrium payoff $(1-\gamma)[\phi(i)-\psi(i)]$ for the buyer and equilibrium payoff $\gamma[\phi(i)-\psi(i)]+\psi(i)-i$ for both types of sellers. By part a) of this proof, any deviation $p^{\prime}>\gamma$ cannot be profitable as it is dominated by $p=\gamma$. Consider a deviation $p^{\prime} \in[0, \gamma[$. Whereas the fair-minded seller rejects by Lemma 2, the expected maximum attainable deviation payoff depends on the acceptance decision of the selfish seller at $p^{\prime}=0$. If the selfish seller accepts all $p^{\prime} \geq 0$, the buyer's optimal deviation is $p^{\prime}=0$, thus generating maximum deviation payoff $(1-\mu)[\phi(i)-\psi(i)]$. If the selfish seller rejects $p^{\prime}=0$, the above maximum deviation payoff can be approximated arbitrarily closely by deviating to $p^{\prime}=\epsilon$ with $\epsilon>0$ but arbitrarily small, which must always be accepted by the selfish seller. Setting $p=\gamma$ thus forms a perfect Bayesian equilibrium if and only if $(1-\gamma)[\phi(i)-\psi(i)] \geq(1-\mu)[\phi(i)-\psi(i)]$, that is if and only if $\mu \geq \gamma$.

c) Consider $p=0$. Whereas the fair-minded seller rejects by Lemma 2 , the selfish seller must accept in equilibrium, as the buyer can otherwise increase his profit by deviating to any $\left.\left.p^{\prime} \in\right] 0, \gamma\right]$. Thus, $p=0$ gives the buyer equilibrium payoff $[1-\mu(i)][\phi(i)-\psi(i)]$, and 
equilibrium payoff $\psi(i)-i$ for both types of sellers. By the argument in part a) and b) of this proof, the buyer's most profitable deviation is $p^{\prime}=\gamma$ generating maximum deviation payoff $(1-\gamma)[\phi(i)-\psi(i)]$. Comparing payoffs, $p=\gamma$ can form a perfect Bayesian equilibrium if and only if $\mu \leq \gamma$.

d) By the above arguments, the two types of pure strategy perfect Bayesian equilibria coexist if and only if $\mu=\gamma$.

Q.E.D.

\section{Proof of Proposition 1}

As the seller's type is observable, the buyer holds belief $\mu^{*}(i)=0$ if the selfish seller, and $\mu^{*}(i)=1$ if the seller is fair-minded. This belief is independent of the seller's investment. For given $i$, equilibrium behavior and payoffs are determined by Lemma 3. Equilibrium investments follow from each type of seller's maximization with respect to $i$. By Lemma 1, equilibrium investments are unique, where $i_{s}<i_{f}<i_{e}$.

Q.E.D.

\section{Proof of Lemma 4}

Proof: a) Since $\gamma>0$ and $\phi(i)-\psi(i)>0$ for all $i$, inequality $\gamma[\phi(i)-\psi(i)]+\psi(i)-i>\psi(i)-i$ holds for all $i$. As $I$ thus includes $i_{0}$, it is non-empty.

b) $\gamma[\phi(i)-\psi(i)]+\psi(i)-i$ is strictly concave by Assumption 3. As $I$ is the upper contour set of this function with respect to $U_{0}, I$ is convex. As the boundaries are included, $I$ forms a closed interval in $\mathbb{R}^{+}$.

c) Suppose $\gamma[\phi(0)-\psi(0)]+\psi(0)-0=\gamma \phi(0) \geq U_{0}$. Then set $\underline{i}=0$. Suppose $\gamma[\phi(0)-\psi(0)]+\psi(0)-0<U_{0}$. Since $\gamma>0$, inequality $U_{0}<\gamma\left[\phi\left(i_{0}\right)-\psi\left(i_{0}\right)\right]+\psi\left(i_{0}\right)$ holds. As $i_{0}<\arg \max _{i}\{\gamma[\phi(i)-\psi(i)]+\psi(i)-i\}$ by Assumption $5, \gamma[\phi(i)-\psi(i)]+\psi(i)-i$ is strictly increasing in $\left[0, i_{0}\right]$ by its concavity. As it is continuous, monotonicity and the mean value theorem imply the existence of a unique $\underline{i} \in] 0, i_{0}[$.

d) Since $\gamma>0$, inequality $\max _{i}\{\gamma[\phi(i)-\psi(i)]+\psi(i)-i\}>U_{0}$ holds. For all $i>$ $\arg \max _{i}\{\gamma[\phi(i)-\psi(i)]+\psi(i)-i\}$, the function $\gamma[\phi(i)-\psi(i)]+\psi(i)-i$ is strictly decreasing. By Assumption 3 and 6, it goes to minus infinity as $i$ goes to plus infinity. As it 
is continuous, its monotonicity and the mean value theorem imply the existence of a unique and finite $\bar{i}$. As $\bar{i}$ is finite, $I$ is bounded.

Q.E.D.

\section{Proof of Proposition 2}

a) Consider a pooling equilibrium with equilibrium investment $i^{*}$. Since there is pooling, the buyer holds belief $\mu^{*}\left(i^{*}\right)=\pi$.

b) By Lemma 3, the buyer's most discouraging equilibrium belief to any out-of-equilibrium investment $i$ is $\mu^{*}(i)=0$, thereby giving both types of sellers a deviation payoff $\psi(i)-i$. The supremum deviation payoff is thus $U_{0}$, which is attainable if and only if $i^{*} \neq i_{0}$. As otherwise there must exist a profitable deviation, $U_{\theta}^{*} \geq U_{0}$ must hold for both $\theta \in\{s, f\}$. This condition is also sufficient since, out-of-equilibrium beliefs can be chosen arbitrarily. Thus, there exists a pooling equilibrium if and only if $U_{\theta}^{*} \geq U_{0}$ for $\theta \in\{s, f\}$.

c) Suppose $\pi \geq \gamma$. By Lemma 3 and $\gamma$, the maximum equilibrium payoff for both types of sellers is given by $\gamma\left[\phi\left(i^{*}\right)-\psi\left(i^{*}\right)\right]+\psi\left(i^{*}\right)-i^{*}$. By part b) of this proof and the very definition of $I$, investment $i^{*}$ can thus be supported in equilibrium if and only if $i^{*} \in I$. As for all $\gamma>0$ the set $I$ is non-empty by Lemma 4 , such pooling equilibria exist.

d) Suppose $\pi<\gamma$. By Lemma 3, both types $\theta \in\{s, f\}$ of seller get equilibrium payoff $U_{\theta}^{*}=\psi\left(i^{*}\right)-i^{*}$. Only $i^{*}=i_{0}$ satisfies $U_{\theta}^{*} \geq U_{0}$ as required by part b) of this proof. Thus, $i_{0}$ forms the unique equilibrium investment.

Q.E.D.

\section{Proof of Lemma 5}

a) The selfish seller can always precisely mimic the fair-minded seller and deviate to $i_{s}^{\prime}=i_{f}^{*}$ and $a_{s}^{\prime}\left[p_{b}^{*}\left(i_{f}^{*}\right)\right]=a_{f}^{*}\left[p_{b}^{*}\left(i_{f}^{*}\right)\right]$. Independently of $a^{\prime}\left[p_{b}^{*}\left(i_{f}^{*}\right)\right] \in\{0,1\}$, the selfish seller then gets a deviation payoff weakly larger than the fair-minded seller's equilibrium payoff $U_{f}^{*}$. In every PBE, the selfish seller's equilibrium payoff $U_{s}^{*}$ must exceed all possible deviation payoffs, therefore $U_{s}^{*} \geq U_{f}^{*}$.

b) The fair-minded seller can always mimic the selfish seller's investment and choose $i_{f}^{\prime}=i_{s}^{*}$.

By Lemma 3 , there are only two possible equilibrium proposals of the buyer, $p_{b}^{*}\left(i_{s}^{*}\right)=\gamma$ 
and $p_{b}^{*}\left(i_{s}^{*}\right)=0$. Both these proposals are accepted by the selfish seller. However, suppose the fair-minded seller accepts if and only if $p_{b}^{*}\left(i_{s}^{*}\right)=\gamma$. He then gets a deviation payoff weakly larger than the selfish seller's equilibrium payoff $U_{s}^{*}$ independently of the buyer's equilibrium proposal. In every PBE, the fair-minded seller's equilibrium payoff $U_{f}^{*}$ must exceed all possible deviation payoffs, therefore $U_{f}^{*} \geq U_{s}^{*}$. Together with $U_{s}^{*} \geq U_{f}^{*}$ from part a) of this proof, this implies $U_{s}^{*}=U_{f}^{*}$.

Q.E.D.

\section{Proof of Proposition 3}

a) By the same argument as in part b) of the proof of Proposition 2, inequality $U_{\theta}^{*} \geq U_{0}$ must hold for both $\theta \in\{s, f\}$ in any separating equilibrium. This condition, however, is not sufficient, as both types of sellers must not have incentives to mimic the other type.

b) Consider the equilibrium investment $i_{s}^{*}$ of the selfish seller. As only the selfish seller invests $i_{s}^{*}$, the buyer holds belief $\mu^{*}\left(i_{s}^{*}\right)=0$. By Lemma 3 , he proposes $p_{b}^{*}\left(i_{s}^{*}\right)=0$. The selfish seller accepts, thereby receiving equilibrium payoff $U_{s}^{*}=\psi\left(i_{s}^{*}\right)-i_{s}^{*}$. As $U_{s}^{*} \geq U_{0}$ by part a) of this proof, the selfish seller's equilibrium investment is uniquely determined by $i_{s}^{*}=i_{0}$

c) Consider the equilibrium investment $i_{f}^{*}$ of the fair-minded seller. As only the fair-minded seller invests $i_{f}^{*}$, the buyer holds belief $\mu^{*}\left(i_{f}^{*}\right)=1$. By Lemma 3 , he proposes $p_{s}\left(i_{s}^{*}\right)=\gamma$. The fair-minded seller accepts, thereby receiving $U_{f}^{*}=\gamma\left[\phi\left(i_{f}^{*}\right)-\psi\left(i_{f}^{*}\right)\right]+\psi\left(i_{f}^{*}\right)-i_{f}^{*}$. As $U_{s}^{*}=U_{f}^{*}$ by Lemma 5 , the fair-minded seller's equilibrium investment is either $\bar{i}$ or $\underline{i}$, the boundaries of $I$ as defined in Lemma 4 .

d) As $\mu^{*}(\dot{)}=0$ may be chosen for any out-of-equilibrium investment, inequality $U_{\theta}^{*} \geq U_{0}$ for both $\theta \in\{s, f\}$ implies that no type of seller has incentives to deviate to any out-of-equilibrium investment $i$. If the selfish seller mimics the fair-minded seller's investment, he optimally accepts $p_{b}^{*}\left(i_{f}^{*}\right)=\gamma$, thereby receiving deviation payoff $\gamma\left[\phi\left(i_{f}^{*}\right)-\psi\left(i_{f}^{*}\right)\right]+\psi\left(i_{f}^{*}\right)-i_{f}^{*}=U_{f}^{*}$. If the fair-minded seller mimics the selfish seller's investment, he optimally rejects $p_{b}^{*}\left(i_{s}^{*}\right)=0$, thereby receiving deviation payoff $\psi\left(i_{s}^{*}\right)-i_{s}^{*}=U_{s}^{*}$. As $U_{f}^{*}=U_{s}^{*}$, both types of sellers have no incentives to mimic the other type. 
e) The proof of Lemma 4 implies the existence of investments $\bar{i}$ or $\underline{i}$, and thus the existence of the above characterized separating equilibria.

Q.E.D.

\section{Proof of Proposition 5}

a) Consider a pooling equilibrium with equilibrium investment $i^{*}$ and plausible beliefs, that is $\mu^{*}(i)=0$ for all $i<i^{*}$, and $\mu^{*}(i)=1$ for all $i>i^{*}$. Suppose the seller deviates and invests $i^{\prime}$. By Lemma 3 both types get deviation payoff $\psi\left(i^{\prime}\right)-i^{\prime}$ if $i^{\prime}<i^{*}$, and deviation payoff $\gamma\left[\phi\left(i^{\prime}\right)-\psi\left(i^{\prime}\right)\right]+\psi\left(i^{\prime}\right)-i^{\prime}$ if $i^{\prime}>i^{*}$.

b) As $\psi\left(i^{\prime}\right)-i^{\prime} \leq U_{0} \leq U_{\theta}^{*}$ for both types $\theta$, any deviation $i^{\prime}<i^{*}$ cannot be profitable. By Assumption 3, the function $\gamma[\phi(i)-\psi(i)]+\psi(i)-i$ is strictly concave with unique maximizer $i_{f}$. As otherwise there exists a profitable deviation $\left.\left.i^{\prime} \in\right] i^{*}, i_{f}\right]$, any pooling equilibrium with plausible beliefs must have $i^{*} \geq i_{f}$.

c) Suppose $\pi<\gamma$. Proposition 2 determines $i_{0}$ as the equilibrium investment $i^{*}$ in the unique pooling equilibrium. As $i_{0}<i_{f}$ by Lemma 1 , there exists no pooling equilibrium with plausible beliefs. Suppose $\pi \geq \gamma$. As $i_{f} \in I, \gamma>0$, and by definition of the set $I$, there exists a continuum of pooling equilibria with equilibrium investment $i^{*}$ satisfying both $i^{*} \in I$ and $i \geq i_{f}$.

Q.E.D. 


\section{References}

Bolton, G. E., And A. Ockenfels (2000): "ECR: A Theory of Equity, Reciprocity, and Competition," American Economic Review, 90(1), 166-193.

Camerer, C., and R. Thaler (1997): "Ultimatums, Dictators, and Manners," Journal of Economic Perspectives, 64, 209-219.

Carmichael, L., and W. B. MacLeod (2003): "Caring about Sunk Costs: A Behavioural Solution to Hold-Up Problems with Small Stakes," Journal of Law, Economics and Organization, 19(1), 106-118.

Cho, I.-K., And D. M. Kreps (1987): "Signalling Games and Stable Equilibria," Quarterly Journal of Economics, 102, 179-221.

Crawford, V. P. (1982): "A Theory of Disagreement in Bargaining," Econometrica, 50(3), $607-638$.

Ellingsen, T., and M. Johannesson (2002a): "Is there a Hold-Up Problem?," forthcoming in Scandinavian Journal of Economics.

- (2002b): "Sunk Costs and Fairness in Incomplete Information Bargaining," forthcoming in Games and Economic Behavior.

(2004): "Promises, Threats, and Fairness," Economic Journal, 114.

Ellingsen, T., And J. Robles (2002): "Does Evolution Solve the Hold-Up Problem," Games and Economic Behavior, pp. 28-53.

Ewerhart, C. (2004): "The Effect of Sunk Costs on the Outcome of Alternating-Offers Bargaining between Inequity Averse Agents," GEABA Discussion Paper 04-35.

Fehr, E., And K. M. Schmidt (1999): "A Theory of Fairness, Competition, and Cooperation," Quarterly Journal of Economics, 114(3), 817-868.

Grossman, S., and O. Hart (1986): "The Costs and Benefits of Ownership: a Theory of Lateral and Vertical Integration," Journal of Political Economy, 94, 691-719.

Grout, P. (1982): "Investments and Wages in the Absence of Binding Contracts: A Nash Bargaining Approach," Econometrica, 52, 449-460. 
Gul, F. (2001): "Unobservable Investment and the Hold-Up Problem," Econometrica, 69(2), 343-376.

Güth, W., R. Schmittberger, and R. Tietz (1990): "Ultimatum Bargaining Behaviour - A Survey and Comparison of Experimental Results," Journal of Economic Psychology, $11,417-449$.

Hart, O., And J. Moore (1990): "Property Rights and the Nature of the Firm," Journal of Political Economy, 98, 1119-1158.

Holmströм, B. (1982): "Moral Hazard in Teams," Bell Journal of Economics, 13, 324-340.

Laffont, J.-J., And J. TiRole (1993): A Theory of Regulation and Procurement. Cambridge, MIT Press.

Mas-Colell, A., M. D. Whinston, and J. R. Green (1995): Microeconomic Theory. Oxford University Press.

Rabin, M. (1993): "Incorporating Fairness into Game Theory and Economics," American Economic Review, 83(5), 1281-1302.

TröGER, T. (2002): "Why Sunk Costs Matter for Bargaining Outcomes: An Evolutionary Approach," Journal of Economic Theory, 102, 375-402.

von Siemens, F. A. (2004): "Inequity Aversion and Incentives: Three Essays in Microeconomic Theory," Ph.D. Thesis, University of Munich, available at http://edoc.ub.uni-muenchen.de/archive/00002756/. 